\title{
Pengelolaan Arsip Secara Digital Menggunakan Algoritma LZSS Modifikasi untuk Kompresi File
}

\author{
Sujono $^{\# 1}$, Maxrizal ${ }^{\# 2}$, Dian Novianto ${ }^{* 3}$ \\ ${ }^{\#}$ Jurusan Sistem Informasi, STMIK Atma Luhur \\ Jl. Jendral Sudirman, Kel. Selindung Baru, Kec. Pangkal Balam, Pangkal Pinang, Kepulauan Bangka Belitung \\ ${ }^{1}$ sujonodatmaluhur.ac.id \\ 2maxrizaleatmaluhur.ac.id \\ *Jurusan Teknik Informatika \\ Jl. Jendral Sudirman, Kel. Selindung Baru, Kec. Pangkal Balam, Pangkal Pinang, Kepulauan Bangka Belitung \\ ${ }^{3}$ diannoviantodatmaluhur.ac.id
}

\begin{abstract}
Abstrak-Dokumen yang menumpuk dalam bentuk hardcopy dapat menimbulkan suatu masalah, baik dalam penataan, keamanan dokumen maupun ruang penyimpanan dokumen. Selain itu perawatan ekstra diperlukan untuk mencegah kerusakan pada dokumen penting yang disebabkan oleh serangga dan lain-lain. Dengan teknologi sekarang ini dokumen dapat disimpan dalam bentuk file dan sekaligus ukuran file dapat diperkecil untuk meminimalkan media penyimpanan dan penyusunan dokumen dapat ditata dengan baik sehingga pada saat pencarian dokumen menjadi lebih mudah. File merupakan data digital yang berisi informasi. Untuk memperkecil ukuran file yaitu dengan cara dipadatkan atau biasa disebut dengan kompresi sehingga ukuran file menjadi lebih kecil dari ukuran semula. Pada penelitian ini, metode yang digunakan untuk kompres file adalah LZSS (Lempel Ziv Strorer-Szymanski) yang telah dimodifikasi untuk menghasilkan kompres yang lebih optimal. Algoritma kompresi LZSS modifikasi dikembangkan berdasarkan konsep algoritma kompresi LZSS (pengkodean (offset,len)) serta penambahan pengkodean (offset,-len). Dari 9 sampel file yang dipilih sebagai data simulasi, diperoleh rata-rata rasio kompresi algoritma LZSS adalah $\mathbf{7 5 , 4 0 \%}$ dan rata-rata kompresi algoritma LZSS modifikasi adalah $67,86 \%$. Hal ini menunjukkan bahwa algoritman LZSS modifikasi menghasilkan tingkat kompresi yang lebih baik.
\end{abstract}

Kata kunci - LZSS, kompresi file, modifikasi, rasio kompresi, pengelolaan arsip.

\section{PEndahuluan}

Penyimpanan arsip dokumen menjadi suatu perhatian yang sangat penting, baik dari sisi keamanan, perawatan maupun ruang simpan arsip itu sendiri. Banyak instansi pemerintahan maupun swasta masih menggunakan teknik pengarsipan dengan metode penyimpanan fisik arsip berupa hardcopy sehingga kemanan, perawatan, dan pencarian arsip masih mengalami kesulitan. Untuk mengatasi hal ini, salah satu solusinya adalah arsip disimpan dalam bentuk digital yang dapat dikelola oleh sebuah Sistem Informasi. Saat ini, sistem informasi dalam dunia teknologi informasi bukanlah hal yang baru. Kita dapat membangun sebuah sistem yang dapat menyimpan arsip dengan kode tertentu agar pencarian arsip dapat dilakukan lebih cepat [1]. Dalam hal memaksimalkan ruang penyimpanan, ukuran arsip juga dapat dipadatkan dengan teknik kompresi dokumen.

Ada banyak teknik kompresi dokumen yang berbasis pohon biner dan dictionary (kamus). Salah satu teknik kompresi data yang berbasis dictionary yang banyak digunakan adalah algoritma kompresi LZSS. Algoritma kompresi ini merupakan pengembangan dari algoritma kompresi LZ77 yang dikembangkan oleh Lempel-ZivStorer-Szymanski dan telah banyak dikembangkan. Algoritma ini telah dikembangkan dengan beberapa kombinasi untuk optimalisasi kompresi dengan algoritma lainnya, seperti LZW dan Huffman [2]-[5]. Selain itu, telah banyak perbaikan dari error yang dihasilkan dari algoritma kompresi LZSS untuk menghasilkan algoritma LZSS yang lebih optimal [3], [4], [6]-[12]. Algoritma ini juga telah dimodifikasi pada desain dan konsep yang baru [13], [14].

Pada prinsipnya, algoritma kompresi LZSS bekerja dengan mengkodekan substring yang sama dengan string yang tidak dikodekan. Pada algoritma ini dikenal istilah (offset, len). Offset adalah banyaknya karakter sampai pointer tertentu dan len adalah panjang string yang cocok (matching string).

Misalnya diberikan teks asli T:abcdbcde, sehingga menurut algoritma kompresi LZSS dienkode menjadi $E(T): a b c d(1,3) e$ [8]. Dengan demikian, terdapat (offset, len $)=(1,3)$ yang mewakili karakter setelah pointer ke-1 sepanjang 3 karakter yang sama berikutnya. Jika kita lihat lebih detail, kekuatan algoritma kompresi ini terletak pada pengkodean string atau substring yang cocok (matching). Perhatikan juga bahwa (offset, len) dapat kita artikan sebagai banyaknya langkah maju (berikutnya) dari pointer yang ditetapkan. 
Untuk mengoptimalkan hasil kompres data maka pada awal penelitian ini akan dikembangkan modifikasi pada (offset, len) konsep langkah mundur (sebelumnya), sehingga konsep yang digunakan pada algoritma adalah langkah maju dan konsep langkah mundur (sebelumnya) dari pointer yang ditetapkan. Hal ini berarti konsep LZSS asli tetap dipakai, selanjutnya ditambahkan langkah mudur atau dinamai (offset, -len) artinya banyaknya langkah mundur (sebelumnya) dari pointer yang ditetapkan. Selanjutnya, pada tahap akhir, konsep algoritma kompresi LZSS modifikasi ini akan dibuatkan menjadi aplikasi.

\section{METODOLOGI PENELITIAN}

Penelitian ini merupakan penelitian kajian pustaka dan penelitian terapan (implementasi). Pada tahap pertama, teori-teori algoritma LZSS dan pengembangan yang telah dilakukan dikaji melalui beberapa jurnal. Selanjutnya, tahap kedua dinyatakan dalam fase berikut ini:.

\section{A. Model Pengembangan Penelitian}

Untuk pengembangan model sistem, tahapan penelitian digambarkan dengan bagan alir (Gambar 1).

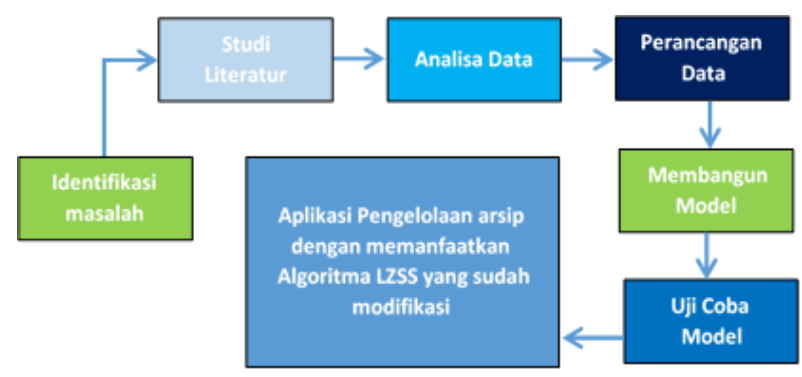

Gambar. 1 Pengembangan model sistem

\section{B. Model Proses Pengelolaan arsip dengan sistem}

Untuk model sistem pengelolaan arsip saat arsip diunggah sampai arsip tersimpan diruang penyimpanan (Gambar2).

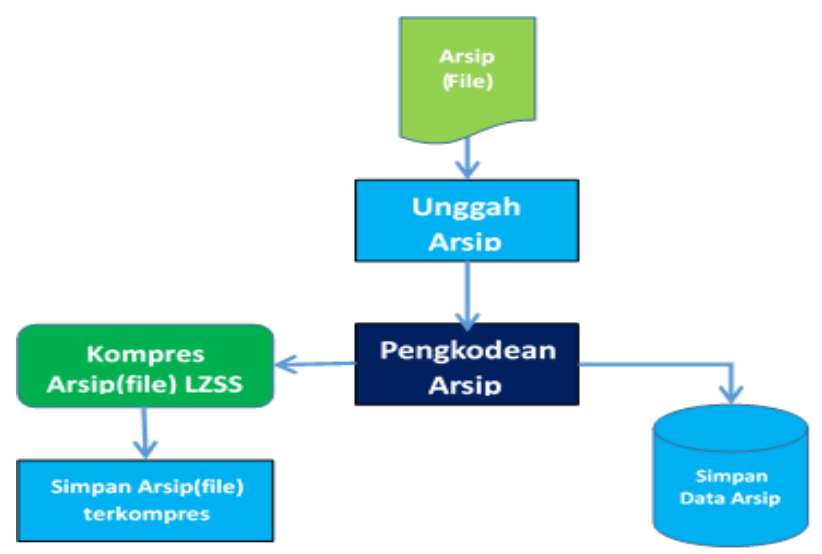

Gambar. 2 Model Proses Penglolaan Arsip

\section{HASIL DAN PEMBAHASAN}

A. Algoritma Kompresi LZSS
Algoritma kompresi LZSS merupakan salah satu algoritma kompresi yang berbasis dictionary (kamus). Algoritma ini merupakan pengembangan dari algoritma kompresi LZ77. Pada algoritma kompresi LZSS, teks dikodekan sebagai pasangan terurut (offset,len), yaitu offset adalah banyaknya karakter sampai karakter pada pointer yang ditetapkan dan len adalah panjang string yang cocok.

\section{B. Ide Pengembangan Algoritma Kompresi LZSS Modifikasi}

Misalkan diberikan teks asli T:abcdebcddcbb maka dengan konsep algoritma kompresi LZSS diperoleh hasil enkode $E(T): a b c d e(1,3) d c b b$. Perhatikan bahwa teks asli ada 12 karakter dan setelah dienkode dengan algoritma kompresi LZSS menjadi 11 karakter. Jika diperhatikan lebih detail maka hanya string "bcd" yang dapat disimbolkan menjadi $(1,3)$ artinya setelah karakter ke-1 ada kesamaan sepanjang 3 karakter selanjutnya.

Perhatikan kembali teks asli T:abcdebcddcbb. Kita dapat megenkode $E(T): a b c d(1,3)(5,-3) b$ dengan jumlah 9 karakter, lebih sedikit dari output enkode algoritma kompresi LZSS. Perhatikan bahwa string " $d c b$ " dapat dibaca $(5,-3)$ artinya saat pointer pada karakter 5 maka terdapat kesamaan jika mundur 3 langkah. Hal inilah yang melatarbelakangi ide pengembangan konsep modifikasi pada algoritma kompresi LZSS. Jadi, pada algoritma kompresi LZSS berlaku pengkodean (offset,len) maka pada modifikasinya yang diusulkan berlaku (offset,len) dan (offset,-len).

\section{Analisis Algoritma Kompresi LZSS Modifikasi}

Algoritma yang diusulkan menggunakan pengkodean (offset,len) dan (offset,-len). Dengan demikian terjadi 3 kondisi di bawah ini:

1) Terdapat (offset,len) dan (offset,-len) pada string yang berbeda: Jika pengkodean (offset,len) dan (offset,len) terjadi pada string yang berbeda maka output dari pengkodean algoritma LZSS modifikasi merupakan gabungan keduanya. Selanjutnya, diberikan contoh teks asli di bawah ini.

- 0:tes nama kamu

- 14:kaset kamu

Perhatikan bahwa teks ini terdiri atas 24 karakter. Jika dikerjakan dengan algoritma kompresi LZSS diperoleh hasil enkode berupa:

- 0:tes nama kamu

- $14: \operatorname{kaset}(8,5)$

Total karakter pada output enkode algoritma kompresi LZSS adalah 21 karakter. Jika dikerjakan pada algoritma kompresi LZSS modifikasi yang diusulkan menghasilkan output:

- 0:tes nama kamu

- $14: \operatorname{ka}(4,-3)(8,5)$

Total karakter output enkode pada algoritma kompresi LZSS modifiksi adalah 20 karakter. Perhatikan bahwa terdapat 1 kode (offset,len) dan 1 kode (offset,-len) yang 
berbeda yaitu $(8,5)$ dan(4,-3). Perhatikan bahwa penggunaan algoritma kompresi LZSS modifikasi yang diusulkan menghasilkan jumlah karakter yang lebih sedikit (optimal).

2) Terdapat (offset,len) dan (offset,-len) pada string yang sama dengan panjang sama: Jika pengkodean (offset,len) dan (offset,-len) terjadi pada string yang sama dengan panjang sama maka output dari pengkodean algoritma LZSS modifikasi adalah pengkodean (offset,len). Selanjutnya, diberikan contoh teks asli di bawah ini.

- 0:nama kamu

- 10:kamu rama

Perhatikan bahwa teks ini terdiri atas 19 karakter. Jika dikerjakan dengan algoritma kompresi LZSS diperoleh hasil enkode berupa:

- 0:nama kamu

- 10:(5,4) r $(1,3)$

Total karakter pada output enkode algoritma kompresi LZSS adalah 16 karakter. Jika, dikerjakan pada algoritma kompresi LZSS yang diusulkan menghasilkan output:

- 0:nama kamu

- $10:(5,4) \mathrm{r}(1,3)$

Total karakter output enkode pada algoritma kompresi LZSS modifiksi yang diusulkan adalah 16 karakter. Perhatikan bahwa pada algoritma kompresi LZSS modifikasi "ama” pada string rama dapat dikodekan $(1,3)$ atau $(5,-3)$.

3) Terdapat (offset,len) dan (offset,-len) pada string yang sama dengan panjang berbeda: Jika pengkodean (offset,len) dan (offset,-len) terjadi pada string yang sama dengan panjang berbeda maka output dari pengkodean algoritma LZSS modifikasi merupakan hasil pengkodean terpanjang yang dihasilkan dari keduanya. Selanjutnya, diberikan contoh teks asli di bawah ini.

- 0:kamu makan

- 11:kamu nakal

Perhatikan bahwa teks ini terdiri atas 21 karakter. Jika dikerjakan dengan algoritma kompresi LZSS diperoleh hasil enkode berupa:

- $0:$ kamu makan

- $11:(0,5) \mathrm{n}(6,3) 1$

Total karakter pada output enkode algoritma kompresi LZSS adalah 17 karakter. Jika, dikerjakan pada algoritma kompresi LZSS modifikasi yang diusulkan akan menghasilkan output enkode:

- $0:$ kamu makan

- $11:(0,5)(10,-4) 1$

Total karakter output enkode pada algoritma kompresi LZSS modifiksi adalah 16 karakter. Perhatikan bahwa pada algoritma kompresi LZSS pada string "nakal" dienkode menjadi " $n(6,3) l$ " yang berarti hanya 3 karakter yang sama dikodekan. Sedangkan, pada algoritma kompresi LZSS modifikasi "naka" pada string "nakal" dapat dikodekan $(10,-4)$. Jadi pengkodean terpanjang diperoleh pada kode $(10,-4)$.
Secara umum, jika tidak ada string yang bisa dibalik (dibaca mundur) maka algoritma kompresi LZSS yang diusulkan sama dengan algoritma kompresi LZSS. Pada faktanya, semakin banyak string atau kata yang terdapat dalam satu dokumen, pasti semakin banyak string atau kata yang berulang sehingga konsep algoritma kompresi LZSS modifikasi dapat diterapkan agar pengkompresan data menjadi lebih optimal.

\section{Simulasi Perbandingan Algoritma Kompresi LZSS dan Algoritma Kompresi LZSS Modifikasi}

Pada penelitian ini, perbandingan algoritma kompresi LZSS dan algoritma kompresi LZSS modifikasi akan dinyatakan dalam rasio kompresi [13]. Kami menggunakan definisi rasio kompresi $c$ dengan persamaan

$$
c=\frac{\text { ukuran }(\text { data terkompresi })}{\text { ukuran }(\text { data tidak terkompresi })}
$$

Misalkan ukuran asli suatu file (ukuran data tidak terkompresi) adalah 40 karakter. Selanjutnya, setelah dikompresi ukurannya (ukuran data terkompresi) menjadi 25 karakter. Dengan demikian, rasio kompresi file itu adalah $c=62,5 \%$. Perhatikan bahwa semakin kecil rasio kompresi maka tingkat kompresi semakin baik.

Berikut ini diberikan original teks asli (data yang belum dikompresi).

- 0:saya suka makan ayam

- 21:aku suka makan nasi

- 41:maya anak nakal

- 57:disana sangat aman

- 76:namaku maya

Jadi, terdapat total 87 karakter (ukuran data tidak terkompresi). Perbandingan hasil kompresi algoritma kompresi LZSS dan algoritma kompresi LZSS modifikasi yang diusulkan dapat dilihat pada Tabel 1.

TABEL I

PERBANDINGAN HASIL KOMPRESI ALGORITMA KOMPRESI LZSS DAN ALGORITMA KOMPRESI LZSS MODIFIKASI PADA DATA SIMULASI

\begin{tabular}{|l|l|}
\hline Algoritma Kompresi & Algoritma Kompresi LZSS \\
LZSS & Modifikasi \\
\hline 0:saya suka makan ayam & 0:saya suka makan ayam \\
21:aku(4,12)nasi & 21:(10,-3)(4,12)nasi \\
31:m(16,3) anak nakal & 30:(21,-5)a (16,-3) $(16,-4) 1$ \\
46:disana sangat aman & 40:disana sangat aman \\
65:namaku m(16,3) & 59:(59,-4)ku $(21,-4)$ \\
\hline 75 karakter & 66 karakter \\
\hline
\end{tabular}

Pada simulasi ini, rasio kompresi algoritma LZSS $=\frac{75}{87}=0,86$ atau $86 \%$ dan rasio kompresi LZSS modifikasi $=\frac{66}{87}=0,76$ atau $76 \%$. Pada kasus ini rasio kompresi algoritma LZSS modifikasi lebih kecil 10\% dari rasio kompresi algoritma LZSS yang berarti algoritma LZSS modifikasi memiliki tingkat kompresi yang lebih baik. 


\section{E. Penerapan Algoritma Kompresi LZSS modifikasi}

Konsep algoritma kompresi LZSS modifikasi yang diusulkan diterapkan pada interface Data Penelitian, Data Pengabdian, dan Data Kerjasama LPPM STMIK Atma Luhur. Sebelum file disimpan diruang penyimpanan maka file dikompres terlebih dahulu dengan algoritma LZSS modifiksi.

Proses kompresi file dimulai dengan pemilihan file yaitu dengan menekan button "CARI FILE". Jika file yang dicari telah ditemukan maka selanjutnya tekan button "COMPRES". Output kompresi akan berupa tabel. Berikut ini adalah tampilan aplikasi setelah melakukan proses kompresi salah satu file.

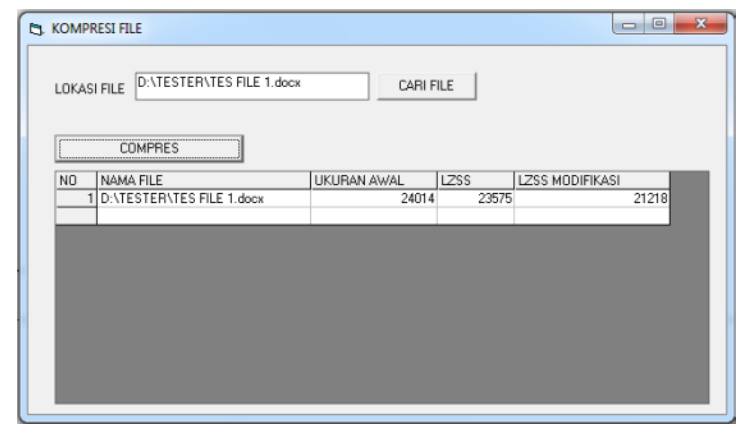

Gambar. 3 Tampilan aplikasi

Aplikasi akan menampilkan hasil kompresi algoritma LZSS dan kompresi algoritma LZSS modifikasi. Selanjutnya, berikut ini tampilan aplikasi untuk kompresi pada beberapa file inputan.

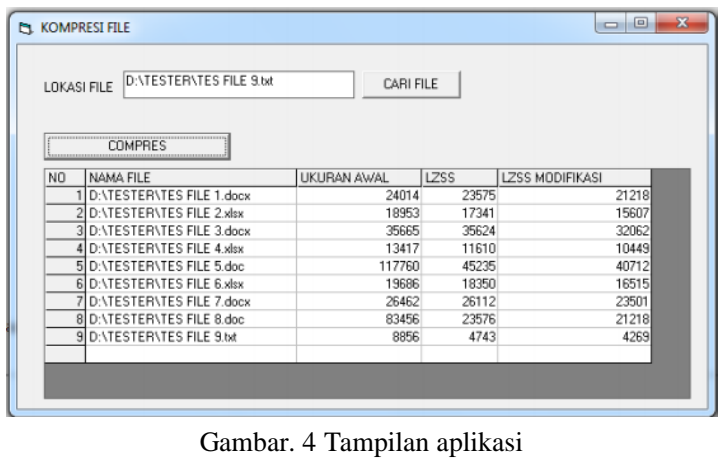

Pada simulasi di atas, kami memilih 9 sampel file dalam beberapa format (.docx, .doc, . $x l s x$, .txt). Berikut ini tabel output simulasi kompresi file.

Berdasarkan Tabel 2, ukuran data hasil kompresi LZSS modifikasi cendrung selalu lebih kecil dari pada hasil kompresi algoritma LZSS. Dari 9 sampel file diperoleh rata-rata rasio kompresi algoritma LZSS adalah 75,40\% dan rata-rata kompresi algoritma LZSS modifikasi adalah $67,86 \%$. Hal ini menunjukkan bahwa algoritman LZSS modifikasi menghasilkan tingkat kompresi yang lebih baik.
TABEL II

PERBANDINGAN UKURAN FILE PADA ALGORITMA KOMPRESI LZSS DAN ALGORITMA KOMPRESI LZSS MODIFIKASI

\begin{tabular}{|c|c|c|c|c|c|}
\hline $\begin{array}{c}\text { N } \\
\text { o }\end{array}$ & $\begin{array}{c}\text { Ukuran } \\
\text { (byte) }\end{array}$ & LZSS & LZSS* & $\begin{array}{c}\text { Rasio } \\
\text { LZSS }\end{array}$ & $\begin{array}{c}\text { Rasio } \\
\text { LZSS* }\end{array}$ \\
\hline 1 & 24014 & 23575 & 21218 & $98,17 \%$ & $88,36 \%$ \\
\hline 2 & 18953 & 17341 & 15607 & $91,49 \%$ & $82,35 \%$ \\
\hline 3 & 35665 & 35624 & 32062 & $99,89 \%$ & $89,90 \%$ \\
\hline 4 & 13417 & 11610 & 10449 & $86,53 \%$ & $77,88 \%$ \\
\hline 5 & 117760 & 45235 & 40712 & $38,41 \%$ & $34,57 \%$ \\
\hline 6 & 19686 & 18350 & 16515 & $93,21 \%$ & $83,89 \%$ \\
\hline 7 & 26462 & 23576 & 21218 & $89,09 \%$ & $80,18 \%$ \\
\hline 8 & 83456 & 23576 & 21218 & $28,25 \%$ & $25,42 \%$ \\
\hline 9 & 8856 & 4743 & 4269 & $53,56 \%$ & $48,20 \%$ \\
\hline \multicolumn{7}{|c|}{ Rata-rata rasio kompresi } & $\mathbf{7 5 , 4 0 \%}$ & $\mathbf{6 7 , 8 6 \%}$ \\
\hline
\end{tabular}

\section{KESIMPULAN}

Algoritma kompresi LZSS modifikasi dikembangkan berdasarkan konsep algoritma kompresi LZSS (pengkodean (offset,len)) serta penambahan pengkodean (offset,-len). Dari 9 sampel file yang dipilih sebagai data simulasi, diperoleh rata-rata rasio kompresi algoritma LZSS adalah $75,40 \%$ dan rata-rata kompresi algoritma LZSS modifikasi adalah $67,86 \%$. Hal ini menunjukkan bahwa algoritman LZSS modifikasi menghasilkan tingkat kompresi yang lebih baik.

\section{UCAPAN TERIMA KASIH / ACKNOWLEDGMENT}

Tim Peneliti mengucapkan banyak terima kasih kepada STMIK Atma Luhur yang telah mensupport pendanaan penelitian ini melalui Hibah Internal Kampus Tahun Anggaran 2019. Tim Peneliti juga berharap hasil penelitian ini dapat dimanfaatkan secara maksimal di Lembaga Penelitian dan Pengabdian Masyarakat STMIK Atma Luhur.

\section{REFERENSI}

[1] Sujono, "Prototipe Aplikasi Pengelolaan Arsip Dalam Format Digital," Konf. Nas. Sist. Inf. 2018 STMIK, pp. 653-656, 2018.

[2] Y. JIng, "The Combinational Application of LZSS and LZW Algorithms for Compression Based On Huffman," 2011 Int. Conf. Electron. Optoelectron. (ICEOE 2011), pp. 397-399, 2011.

[3] Y. Wiseman, "THE RELATIVE EFFICIENCY OF DATA COMPRESSION BY LZW AND LZSS," Data Sci. J., vol. 6, no. January, pp. 1-6, 2007.

[4] G. Little and J. Diamond, "Optimum String Match Choices in LZSS,” 2010 Data Compression Conf. Optim., 2010.

[5] L. Heng, G. Fei, X. Yanming, and F. Shuo, "The application of LZSS in the RFID tags," 2009 Int. Symp. Comput. Netw. Multimed. Technol., pp. 1-4, 2009.

[6] Z. C. Pereira, M. E. Pellenz, R. D. Souza, and M. A. Arau, "Unequal error protection for LZSS compressed data using ReedSolomon codes," IET Commun, vol. 1, no. 4, pp. 612-617, 2007.

[7] R. Demo, S. Marcelo, and E. Pellenz, "On unequal error protection for LZSS compressed data," Ann. Telecommun, no. 65, pp. 285-292, 2010.

[8] A. Ozsoy and M. Swany, "CULZSS: LZSS Lossless Data Compression on CUDA," 2011 IEEE Int. Conf. Clust. Comput. CULZSS, 2011.

[9] W. Chang, X. Yun, N. Li, and X. Bao, "Investigating Randomness of the LZSS Compression Algorithm," 2012 Int. Conf. Comput. Sci. Serv. Syst. Investig., no. 1, pp. 2001-2006, 2012.

[10] P. Pylak, "Efficient modification of LZSS compression algorithm," Ann. UMCS Inform., vol. 1, no. 2003, pp. 61-72, 2019.

[11] I. Shcherbakov, C. Weis, and N. Wehn, "A High-Performance 
FPGA-Based Implementation of the LZSS Compression Algorithm," 2012 IEEE 26th Int. Parallel Distrib. Process. Symp. Work. PhD Forum, 2012

[12] A. Ozsoy, M. Swany, and A. Chauhan, "Optimizing LZSS Compression on GPGPUs," Futur. Gener. Comput. Syst., 2013.

[13] R. I`sa and Ji r'1 Matou`sek, "A Novel Architecture for LZSS
Compression of Configuration Bitstreams Within FPGA," 2017 IEEE 20th Int. Symp. Des. Diagnostics Electron. Circuits Syst., 2017.

[14] S. T. Klein and D. Shapira, "A New Compression Method for Compressed Matching," Proc. DCC 2000. Data Compression Conf., 2000. 